\title{
ANALISIS NILAI TAMBAH EKONOMIS PADA INDUSTRI RUMAH TANGGA "BERHIAS" DI KOTA PALOPO
}

\author{
M. Risal' \\ Nurul Khusyu'ah Djadid²
}

No. HP $08142436264^{1}$

\section{ABSTRAK}

Penelitian ini bertujuan untuk mengetahui berapa besar nilai tambah ekonomis yang dihasilkan produk tas berbahan dasar sampah anorganik yang di produksi oleh industri rumah tangga "Berhias" di Kota Palopo. Seperti yang kita ketahui, sampah atau limbah merupakan sesuatu yang membahayakan dan jika tidak ditanggulangi dapat memberikan dampak penyakit bagi masyarakat. Padahal, sampah justru dapat mendatangkan nilai ekonomi bagi masyarakat jika diolah menjadi produk-produk bermanfaat. Dasar itulah diadakan penelitian ini, yang diharapkan dapat memberikan pemahaman kepada masyarakat akan manfaat yang didapat dengan mengolah sampah, utamanya sampah anorganik. Penelitian ini menggunakan dasar perhitungan Economi Value Added (EVA) yang merupakan perhitungan ekonomi yang menunjukkan laba yang diperoleh sebuah industri ataupun perusahaan dalam memproduksi sebuah produk, dilihat dari hasil pengurangan biaya yang digunakan selama proses produksi dengan hasil penjualan produk. Berdasarkan hasil analisis Economi Value Added (EVA) dapat diketahui bahwa besarnya nilai tambah yang diperoleh industri rumah tangga "Berhias" dari olahan sampah anorganik Tahun 2010 sebesar Rp.1.530.000, Tahun 2011 sebesar Rp. 2.790.000 dan Tahun 2012 sebesar Rp. 5.940.000. Diharapkan Industri rumah tangga "Berhias" di kota Palopo dapat meningkatkan volume penjualan sehingga memberikan keuntungan atau nilai tambah yang besar pula setiap tahun, untuk kelangsungan hidup industri rumah tangga maupun daerah dalam mengurangi jumlah sampah di kota Palopo.

Kata Kunci: Industri Rumah Tangga "Berhias", Economi Value Added (EVA), sampah anorganik, volume penjualan.

\section{PENDAHULUAN}

Industri merupakan bagian dari pembangunan ekonomi nasional suatu negara, baik di indonesia maupun di negara lain. Itulah mengapa para ahli ekonomi mulai memberikan perhatian mereka kepada perusahaan-perusahaan kecil atau industri karena mereka bagian terbesar dari pekerjaan-pekerjaan baru di dalam perekonomian setiap negara. Oleh karena itu pula, seorang praktisi bisnis maupun mahasiswa dipandang perlu untuk mengetahui tentang arti industri yang berlaku di indonesia maupun di negara lain (Winardi, 2003:80).

Thomas (2008:11-12) mengatakan bahwa semakin banyak wirausahawan yang memulai bisnis berupa industri rumah tangga karena mereka melihat peluang untuk membuat usaha yang menurut mereka penting. Mungkin berupa keinginan mendirikan program daur ulang untuk melestarikan sumber daya bumi yang terbatas, maka dari itu wirausahawan kini menemukan cara untuk mengombinasikan kepedulian sosial mereka dengan keinginan untuk memperoleh kehidupan yang lebih baik. 
Prawirosentono

(2007:241)

berpendapat bahwa, selain dapat memberikan nilai dan manfaat serta dapat memberikan dampak positif untuk pertumbuhan ekonomi suatu negara, industri juga dapat memberikan dampak negatif terhadap lingkungan hidup. Seperti yang kita ketahui bahwa, bukan hanya industri ataupun perusahaan yang dapat menghasilkan limbah tetapi manusia sendiri merupakan makhluk penghasil limbah. Pada zaman purbakala, jumlah manusia di bumi masih sedikit dan kecil pula jumlahnya yang mendiami tiap kawasan pemukiman. Saat itu jumlah limbah yang dihasilkan manusia dapat segera didaur ulang secara alamiah. Artinya, lingkungan alam masih mampu mendaur ulang berbagai jenis limbah yang dihasilkan manusia. Namun pada abad-abad berikutnya, di mana tekhnologi kesehatan dan teknologi untuk mempertinggi kualitas hidup manusia semakin canggih, maka selain jumlah manusia yang semakin banyak, juga kegiatan manusia di berbagai belahan bumi semakin beragam dengan akibat peningkatan pencemaran lingkungan hidup. Lebih-lebih lagi dengan revolusi industri yang dimulai di Inggris menyebar ke berbagai kawasan dunia, mengakibatkan jumlah dan jenis limbah industri yang dihasilkan semakin banyak sehingga tidak mampu didaur ulang secara alamiah. Maka muncul kerusakan lingkungan hidup yang menghancurkan sumber daya hayati yang seharusnya menjadi faktor keseimbangan biologis dan ekologi di bumi. Keseimbangan hidup dan ekosistem di bumi menjadi hancur yang mengancam kelangsungan hidup manusia. Bila generasi manusia saat ini tidak mampu menjaga lingkungan hidup, seyogyanya mereka tidak menyayangi generasi berikutnya karena penderitaan akibat rusaknya lingkungan hidup mereka.

Lingkungan hidup dan pelestarian lingkungan hidup telah menjadi isu penting dalam pembangunan, baik nasional maupun internasional. Implikasi pembangunan nasional suatu negara, selain memberikan dampak positif bagi bangsa itu, ternyata memberikan dampak negatif baik secara nasional, regional, maupun universal. Oleh karena itu, seluruh bangsa di bumi ini yang selalu mengejar kesejahteraan ekonomi melalui berbagai ragam pembangunan masing-masing negara, mengupayakan agar akibat negatif dari pembangunan nasional seminimal mungkin. Tujuannya agar pembangunan yang dilakukan berkelanjutan, karena lingkungan hidupnya terjaga baik dan untuk itu, setiap langkah kegiatan manusia yang dapat mencemari lingkungan bumi harus dapat menghindari kerusakan lingkungan semaksimal mungkin. Limbah manusia dan limbah industri harus dapat dibersihkan agar lingkungan tetap mempunyai daya dukung yang tinggi untuk menjamin kelangsungan hidup manusia dan seluruh sumber daya hayati yang saling berkaitan (Prawirosentono, 2007:241).

Seperti yang kita ketahui, sampah atau limbah merupakan sesuatu yang kecil tetapi jika tidak ditanggulangi dapat 
memberikan dampak yang begitu besar bagi masyarakat. Kita dapat melihat contoh kasus yang paling umum kita temui. Banjir bandang misalnya, yang memberikan kerugian karena banyaknya barang-barang yang rusak karena terkena air, bahkan hal buruk yang dapat ditimbulkan banjir adalah adanya korban jiwa. Contoh lainnya yang umum kita temui atau bahkan pernah kita alami. Demam berdarah, akibat tumpukan sampah anorganik, tempat nyamuk bersarang, yang menyerang banyak manusia dan tidak dipungkiri penyakit ini juga dapat menelan korban jiwa. Akibat yang ditimbulkan dari contoh kasus tersebut tidak lain diakibatkan oleh barang kecil yang bernama sampah.

Apabila kita menyadari bahwa betapa besar dampak yang ditimbulkan oleh sampah yang selama ini kita anggap sepele, ada banyak hal yang dapat kita lakukan, walaupun itu hanya hal-hal kecil, yang mampu mengurangi sekian persen kemungkinan terjadinya musibah banjir atau penyakit demam berdarah. Yang menjadi tugas kita bersama adalah, bagaimana caranya agar sampah dapat kita kelola, sehingga sampah tidak lagi menjadi sumber masalah. Hal terkecil yang semua orang mampu melakukannya dan dapat mengurangi resiko banjir adalah membuang sampah pada tong atau tempat sampah, bahkan masih banyak sekali hal lain yang sebenarnya mampu kita lakukan dengan menggunakan kreatifitas dan inovasi menggunakan sampah, dan secara tidak langsung kita dapat membantu masyarakat terhindar dari masalah.
Di Kota Palopo sendiri sudah ada LSM (Lembaga Swadaya Masyarakat) yang bergerak dalam bidang peduli lingkungan hidup, terkhusus di kelurahan Benteng. Walaupun jumlah anggotanya tidak sebanyak di daerah lain yang peduli dengan lingkungan hidup, tapi ada salah satu kelompok masyarakat di kota Palopo yang sudah berjalan selama 5 tahun dan bergerak dalam industri rumah tangga. Industri rumah tangga yang diberi nama industri rumah tangga "Berhias" ini didirikan oleh seorang guru yang sangat prihatin dengan keadaan di sekitar lingkungannya yang penuh dengan sampah plastik atau sering disebut dengan sampah anorganik. Karena kepeduliannya dengan lingkungan hidup yang didukung oleh suaminya yang juga bekerja di instansi pemerintah yaitu Dinas Kebersihan, akhirnya industri ini berjalan dengan visi mengelola sampah anorganik menjadi sebuah barang yang diharapkan dapat memiliki nilai tambah (value added) dan juga kegiatan ini sebagai salah satu dukungan untuk pemerintah dalam pengolahan sampah menjadi barang yang memiliki nilai.

\section{METODE PENELITIAN}

Dalam penelitian ini, penulis mengadakan penelitian di lokasi usaha yang berada di Palopo, Adapun jenis data yang digunakan dalam penelitian ini adalah: Data kuantitatif yaitu data yang diperoleh berupa angka-angka seperti laporan keuangan dari perusahaan yang diteliti. Sumber data yang 
digunakan yaitu data primer dan data sekunder. Metode pengumpulan data melalui wawancara, pengamatan, dan dokumentasi.

\section{Metode Analisis Data}

Oleh karena setiap alat ukur yang ada memilki beberapa keterbatasan, C.W. Hofer merekomendasi penggunaan pengukuran- nilai tambah dalam mengukur kinerja perusahaan. Nilai tambah (value added) adalah selisih penjualan dan biaya yang dikeluarkan untuk bahan baku dan pembelian material pendukung (Akmal, 2008:1).

S. David Young dan Stephen F. Obyrne dalam kutipan Galamsyah (2012:1) mengemukakan, untuk pengukuran kinerja EVA dapat dihitung sebagai berikut:
Penjualan Bersih

HPP

Laba Kotor

Biaya operasi

Laba operasi sebelum pajak (EBIT)

Pajak (pph)

Laba operasi bersih sesudah pajak (NOPAT)

Biaya modal (modal yang diinvestasikan $\mathrm{x}$ biaya modal)

EVA (Economi Value Added)

Profitabilitas $=\frac{\text { EVA }}{\text { Penjualan Bersih }} \times 100 \%$

\section{HASIL PENELITIAN DAN PEMBAHASAN}

\section{Pembahasan}

1. Akumulasi Harga Pokok Produksi dan Economic Value Added (EVA)

Berikut adalah akumulasi harga pokok produksi tas map berbahan sampah anorganik menggunakan pendekatan Full costing yang dikeluarkan oleh industri rumah tangga "Berhias" Tahun 20102012 :
$\mathrm{XXX}$

$\underline{\mathrm{XXX}}$

XXX

$\underline{X X X}$

XXX

$\underline{\mathrm{XXX}}$

XXX

$\underline{\mathrm{XXX}}$

XXX 


\section{Tabel 1}

HARGA POKOK PRODUKSI TAS MAP BERBAHAN SAMPAH ANORGANIK (Penjualan 300 Lembar) TAHUN 2010

\begin{tabular}{l}
\hline Harga Pokok Produksi (HPP) \\
\hline Pembelian Bahan Baku \\
Pembelian Bahan Pembantu : \\
- Tali tas 300 Meter \\
- Resleting \\
- Kain alas 75 Meter \\
- Benang \\
Total Biaya Bahan Baku dan Bahan Pembantu \\
Biaya Tenaga Kerja \\
Biaya Overhead Tetap \\
- Penyusutan Peralatan dan Bangunan \\
Biaya Overhead Variabel \\
- Biaya Listrik
\end{tabular}

TOTAL HARGA POKOK PRODUK
Rp. 300.000

Rp. 750.000

Rp. 450.000

Rp. 450.000

Rp. $\quad 60.000+$

Rp. 2.010.000

Rp. 1.500 .000

Rp. $\quad 360.000$

Rp. $600.000+$

Rp. 4.470 .000

Tabel 2

HARGA POKOK PRODUKSI TAS MAP BERBAHAN SAMPAH ANORGANIK (Penjualan 500 Lembar) TAHUN 2011

\section{Harga Pokok Produksi (HPP)}

Pembelian Bahan Baku

Rp. $\quad 500.000$

Pembelian Bahan Pembantu :

- Tali tas 500 Meter

Rp. 1.250 .000

- Resleting

- Kain alas 125 Meter

- Benang

Total Biaya Bahan Baku dan Bahan Pembantu Biaya Tenaga Kerja Biaya Overhead Tetap

- Penyusutan Peralatan dan Bangunan

Biaya Overhead Variabel

- Biaya Listrik

TOTAL HARGA POKOK PRODUK
Rp. $\quad 750.000$

Rp. $\quad 750.000$

Rp. $\quad 100.000+$

Rp. 3.350 .000

Rp. 2.500 .000

Rp. 360.000

Rp. $1.000 .000+$

Rp. 7.210 .000 
Tabel 3

HARGA POKOK PRODUKSI TAS MAP BERBAHAN SAMPAH ANORGANIK (Penjualan 1000 Lembar) TAHUN 2012

\begin{tabular}{|c|c|}
\hline Harga Pokok Produksi (HPP) & \\
\hline Pembelian Bahan Baku & Rp.1.000.000 \\
\hline Pembelian Bahan Pembantu & \\
\hline - Tali tas 1.000 Meter & Rp.2.500.000 \\
\hline - Resleting & Rp.1.500.000 \\
\hline - Kain alas 250 Meter & Rp.1.500.000 \\
\hline - Benang & Rp. $200.000+$ \\
\hline Total Biaya Bahan Baku dan Bahan Pembantu & Rp.6.700.000 \\
\hline Biaya Tenaga Kerja & Rp.5.000.000 \\
\hline Biaya Overhead Tetap & \\
\hline - Penyusutan Peralatan dan Bangunan & Rp. 360.000 \\
\hline Biaya Overhead Variabel & \\
\hline - Biaya Listrik & $\underline{\text { Rp. } 2.000 .000}+$ \\
\hline TOTAL HARGA POKOK PRODUK & Rp.14.060.000 \\
\hline
\end{tabular}

Setelah diketahui harga pokok

produksi, maka berikut adalah perhitungan

Economi Value Added:

Tabel 4

PENGUKURAN ECONOMI VALUE ADDED TAS MAP BERBAHAN SAMPAH ANORGANIK (penjualan 300 lembar) TAHUN 2010

\begin{tabular}{ll}
\hline Penjualan bersih & $\mathrm{Rp} \cdot 6.000 .000$ \\
HPP & $\frac{\mathrm{Rp} .4 .470 .000}{\mathrm{Rp} .1 .530 .000}$ \\
Laba kotor & $\underline{\mathrm{Rp} .}$ \\
Biaya operasi & $\mathrm{Rp.1.530.000}$ \\
Laba operasi sebelum pajak & $\underline{\mathrm{Rp} .}$ \\
Pajak & $\mathrm{Rp.1.530.000}$ \\
Laba operasi bersih sesudah pajak & $\underline{\mathrm{Rp}}$ \\
Biaya modal & $\mathrm{Rp} .1 .530 .000$ \\
EVA (Economi Value Added)
\end{tabular}

Sumber : Data diolah 2014 
Profitabilitas 2010

$=\frac{\text { EVA }}{\text { Penjualan Bersih }} \times 100 \%$

$=\frac{R p . .1 .530 .000}{R p .6 .000 .000} \times 100 \%$

$=25,5 \%$
Dari hasil perhitungan menunjukkan persentase profitabilitas tahun 2010 sebesar 25,5\%. Ini berarti bahwa setiap Rp.1.000 dari hasil penjualan tas map berbahan sampah anorganik mampu menghasilkan nilai tambah ekonomis (EVA) sebesar Rp.255.

\section{Tabel 5}

PENGUKURAN ECONOMI VALUE ADDED TAS MAP BERBAHAN SAMPAH ANORGANIK (penjualan 500 lembar) TAHUN 2011
Penjualan bersih
Rp. 10.000 .000
HPP
Rp. 7.210 .000 -
Laba kotor
Rp. 2.790 .000
Biaya operasi
Rp.
Laba operasi sebelum pajak
Rp. 2.790 .000
Pajak
Rp.
Laba operasi bersih sesudah pajak
Rp. 2.790 .000
Biaya modal
$\mathrm{Rp}$
EVA (Economi Value Added)
Rp. 2.790 .000

Sumber : Data diolah 2014

Profitabilitas $2011=\frac{E V A}{\text { Penjualan Bersih }} \times 100 \%$

Dari hasil perhitungan menunjukkan persentase profitabilitas tahun 2011 sebesar 27,9\%. Ini berarti bahwa setiap Rp1.000 dari $=\frac{R p \cdot 2 \cdot 790.000}{R p \cdot 10.000 .000} \times 100 \%$ hasil penjualan tas map berbahan sampah anorganik mampu menghasilkan nilai tambah $=27,9 \%$ ekonomis (EVA) sebesar Rp.279. 
Tabel 6

PENGUKURAN ECONOMI VALUE ADDED TAS MAP BERBAHAN SAMPAH ANORGANIK (penjualan 1000 lembar) TAHUN 2012

\begin{tabular}{ll}
\hline Penjualan bersih & Rp.20.000.000 \\
HPP & $\underline{\text { Rp. } 14.060 .000}$ - \\
Laba kotor & Rp. 5.940 .000 \\
Biaya operasi & $\underline{\text { Rp. }}$ \\
Laba operasi sebelum pajak & Rp. 5.940 .000 \\
Pajak & Rp. \\
Laba operasi bersih sesudah pajak & Rp. 5.940.000 \\
Biaya modal & Rp \\
EVA (Economi Value Added) & Rp. 5.940 .000
\end{tabular}

Sumber : Data diolah 2014

Profitabilitas $2012=\frac{E V A}{\text { Penjualan Bersih }} \times 100 \%$

$$
\begin{aligned}
& =\frac{R p \cdot 5.940 .000}{R p \cdot 20.000 .000} \times 100 \% \\
& =29,7 \%
\end{aligned}
$$

Dari hasil perhitungan menunjukkan persentase profitabilitas tahun 2012 sebesar
29,7\%. Ini berarti bahwa setiap Rp.1.000 dari hasil penjualan tas map berbahan sampah anorganik mampu menghasilkan nilai tambah ekonomis (EVA) sebesar Rp.297.

Jadi, nilai tambah yang diperoleh Industri Rumah Tangga Berhias dalam memproduksi tas map berbahan sampah anorganik tahun 2010-2012 adalah :

Tabel 7

Kesimpulan Hasil Perhitungan HPP dan EVA Tahun 2010-2012

\begin{tabular}{|c|c|c|c|c|}
\hline Tahun & Produksi/lembar & HPP & EVA & $\begin{array}{c}\text { Persentase } \\
\text { Profitabilitas }\end{array}$ \\
\hline 2010 & 300 & Rp. 4.470 .000 & Rp. 1.530 .000 & $25,5 \%$ \\
2011 & 500 & Rp. 7.210 .000 & Rp. 2.790 .000 & $27.9 \%$ \\
2012 & 1.000 & Rp14.060.000 & Rp.5.940.000 & $29,7 \%$ \\
\hline
\end{tabular}

Sumber : Data diolah 2014 
Penjualan tas map berbahan sampah anorganik pada tahun 2010, produksi 300 lembar dengan harga pokok produksi sebesar Rp. 4.470.000, dapat menghasilkan nilai tambah ekonomis (EVA) sebesar Rp. 1.530.000, dengan persentase profitabilitas sebesar $25,5 \%$. Untuk penjualan tahun 2011 , produksi 500 lembar, dengan harga pokok produksi sebesar Rp. 7.210.000, mendapat nilai tambah ekonomis (EVA) sebesar Rp. 2.790.000, dan persentase profitabilitas sebesar $27,9 \%$. Sedangkan pada penjualan tas map berbahan sampah anorganik di tahun 2012, produksi 1.000 lembar, dengan harga pokok produksi sebesar Rp.14.060.000, dan dapat menghasilkan nilai tambah ekonomis (EVA) sebesar Rp.5.940.000, dengan persentase profitabilitas sebesar $29,7 \%$.

Perhitungan di atas menunjukkan bahwa setiap tahun, nilai tambah yang diperoleh industri rumah tangga "Berhias"- mengalami peningkatan. Hal tersebut dilihat dari persentase profitabilitasnya. Tahun 2011 mengalami peningkatan sebesar $2,4 \%$, dan tahun 2012 juga mengalami peningkatan sebesar 1,8\%. Ini dikarenakan penjualan setiap tahunnya meningkat. Apabila setiap tahun volume penjualan industri ini ditingkatkan, secara otomatis nilai tambah yang akan diperoleh juga semakin besar.

2. Analisa Data

Industri rumah tangga "Berhias" di Kota Palopo mengeluarkan modal awal sebesar Rp. 3.000.000 termasuk biaya pembelian 2 mesin jahit seharga Rp.900.000 dan 1 buah pompa air, diluar biaya bangunan yang digunakan selama proses produksi. Lokasi yang digunakan dalam proses produksi adalah teras rumah Ibu Darmawati. Untuk satu lembar tas map, dapat diketahui harga pokok produksinya sebagai berikut :

Tabel 8

HARGA POKOK PRODUK TAS MAP BERBAHAN SAMPAH ANORGANIK

\section{Harga Pokok Produksi (HPP)}

- Pembelian Bahan Baku

Rp. 1.000

- Pembelian Bahan Pembantu :

- Tali tas 1 Meter

Rp. 2.500

- Resleting

Rp. 1.500

- Kain alas $25 \mathrm{~cm}$

Rp. 1.500

- Benang

Rp. $200+$

Jumlah Biaya Bahan Baku dan Bahan Pembantu Rp. 6.700

- Biaya Tenaga Kerja

Rp. 5.000

Biaya Overhead Variabel

- Biaya Listrik

Rp. $2.000+$

TOTAL HARGA POKOK PRODUK

Rp. 13.700 
Jadi, modal untuk satu lembar produk tas map adalah Rp.13.700 sedangkan realisasi harga jual satu lembar produk tas map adalah Rp.20.000. Dengan demikian terdapat selisih efisiensi atau tambahan laba sebesar Rp. 6.300.

Unsur-unsur biaya dalam penentuan harga pokok produksi adalah sebagai berikut :

a. Biaya Bahan Baku

Bahan baku yang digunakan untuk memproduksi tas map berbahan sampah plastik (sampah anorganik) berasal dari pengumpul sampah yang terlebih dahulu memilah antara sampah plastik yang akan dijadikan tas map dengan sampah organik yang mudah terurai oleh tanah. Pengumpul sampah tersebut setiap hari mengantarkan sampah plastik tersebut langsung ke rumah Ibu Darmawati dengan cara dijual. Untuk satu lembar sampah plastik dihargai Rp.500. Untuk produksi 1 lembar tas map digunakan 2 lembar sampah plastik. Jadi, biaya bahan baku untuk 1 lembar tas map adalah Rp.1.000. Untuk mengetahui nilai bahan baku yang digunakan sebagai berikut :

Bahan Baku Tahun 2010

$$
\begin{aligned}
& =\text { Rp. } 1.000 \text { x } 300 \text { lembar } \\
& =\text { Rp. } 300.000
\end{aligned}
$$

Bahan Baku Tahun 2011

$$
\begin{aligned}
& =\text { Rp. } 1.000 \times 500 \text { lembar } \\
& =\text { Rp. } 500.000
\end{aligned}
$$

Bahan Baku Tahun 2012

$$
=\text { Rp. } 1.000 \times 1.000 \text { lembar }
$$$$
=\text { Rp. } 1.000 .000
$$

b. Biaya Tenaga Kerja

Pada usaha ini tenaga kerja yang digunakan sebanyak 2 orang dengan 2 tugas berbeda. Untuk bagian pencucian sampah plastik, dibiayai Rp.1.000 per 2 lembar sampah plastik, sedangkan bagian penjahitan bahan baku hingga menjadi tas dibiayai Rp.4.000 untuk satu lembar tas map. Untuk mengetahui biaya tenaga kerja per tahun adalah sebagai berikut :

1) Biaya Tenaga Kerja Tahun 2010

Upah pencuci bahan baku $=$ Rp. $1.000 \times 300$ lembar $=$ Rp. 300.000

Upah penjahit

$$
=\text { Rp. } 4.000 \text { x } 300 \text { lembar }
$$$$
=\text { Rp. } 1.200 .000
$$

Jadi, biaya tenaga kerja untuk tahun 2010 adalah Rp.1.500.000

2) Biaya Tenaga Kerja Tahun 2011

Upah pencuci bahan baku $=$ Rp. 1.000 x 500 lembar $=$ Rp. 500.000

Upah penjahit

$=$ Rp. $4.000 \times 500$ lembar

$=$ Rp. 2.000 .000

Jadi, biaya tenaga kerja untuk tahun 2011 adalah Rp.2.500.000

3) Biaya Tenaga Kerja Tahun 2012 Upah pencuci bahan baku $=$ Rp. $1.000 \times 1.000$ lembar $=$ Rp. 1.000 .000

Upah penjahit

$=$ Rp. 4.000 x 1.000 lembar 


$$
=\text { Rp. } 4.000 .000
$$

Jadi, biaya tenaga kerja untuk tahun 2012 adalah Rp.5.000.000

c. Biaya Overhead Pabrik

Jenis-jenis biaya overhead yang dapat didefenisikan dalam proses produksi adalah :

1) Biaya Overhead Variable (Biaya listrik)

Biaya listrik tahun 2010

$$
\begin{aligned}
& =\text { Rp. } 2.000 \times 300 \text { lembar } \\
& =\text { Rp. } 600.000
\end{aligned}
$$

Biaya listrik tahun 2011

$$
\begin{aligned}
& =\text { Rp. } 2.000 \times 500 \text { lembar } \\
& =\text { Rp. } 1.000 .000
\end{aligned}
$$

Biaya listrik tahun 2012

$$
\begin{aligned}
& =\text { Rp. } 2.000 \times 1.000 \text { lembar } \\
& =\text { Rp. } 2.000 .000
\end{aligned}
$$

2) Biaya Overhead Tetap (Biaya penyusutan peralatan dan bangunan)

Untuk menghitung biaya penyusutan maka perlu diketahui harga perolehan dan taksiran umur ekonomis dari peralatan serta bangunan yang digunakan dalam proses produksi dengan menggunakan metode garis lurus. Adapun jenis dan umur peralatan dan bangunan yang digunakan adalah sebagai berikut :

Tabel 9

Jenis dan umur peralatan serta bangunan yang digunakan dalam pembuatan tas map berbahan sampah anorganik.

\begin{tabular}{|c|c|c|c|}
\hline No. & Keterangan & Umur & Harga \\
\hline 1. & Mesin Jahit & 5 Tahun & Rp. 900.000 \\
\hline 2. & Mesin Pompa Air 500.000 \\
\hline 3. & Teras Rumah ukuran 4x3 & 5 Tahun & 10 Tahun \\
& meter & & \\
\hline
\end{tabular}

Jadi nilai penyusutan peralatan dan bangunan adalah sebagai berikut :

1. Mesin Jahit $: \frac{R p \cdot 900.000}{5 \text { tahun }}=$ Rp. 180.000

Karena mesin jahit yang digunakan dalam produksi ini sebanyak 2 buah, maka :

Rp. $180.000 \times 2$ buah mesin : Rp. 360.000 Jadi, biaya penyusutan mesin jahit adalah Rp.360.000 per tahun.

2. Mesin Pompa Air : $\frac{R p \cdot 500.000}{5 \text { tahun }}=$ Rp. 100.000 Jadi, biaya penyusutan mesin pompa air adalah : Rp. 100.000 per tahun.
3. Bangunan : $\frac{R p \cdot 2.000 .000}{10 \text { Tahun }}=$ Rp. 200.000 Jadi, biaya penyusutan bangunan adalah : Rp. 200.000 per tahun.

\section{SIMPULAN}

Berdasarkan pembahasan data keuangan dengan menggunakan rumus Economis Value Added (EVA) yang bertujuan untuk mengetahui besarnya nilai tambah yang di peroleh industri rumah tangga "Berhias" dalam mengolah sampah anirganik menjadi 
tas, maka selanjutnya dapat disimpulkan sebagai berikut :

1. Berdasarkan hasil analisis Economi Value Added (EVA) dapat diketahui bahwa besarnya nilai tambah yang diperoleh Industri Rumah Tangga "Berhias" dari olahan sampah anorganik selama tahun 2010 sebesar Rp.1.530.000, tahun 2011 sebesar Rp.2.790.000 dan tahun 2012 sebesar Rp.5.940.000. Hal ini menandakan bahwa selama periode ini, industri Rumah Tangga "Berhias" mampu memperoleh nilai tambah ekonomis dari tas map hasil olahan sampah anorganik.

2. Berdasarkan perhitungan profitabilitas untuk persentase nilai tambah yang diperoleh industri rumah tangga "Berhias" di Kota Palopo, dapat disimpulkan bahwa besar persentase nilai tambah yang diperoleh dari tahun 2010 sebesar 25,5\%, tahun 2011 sebesar 27,9\% dan tahun 2012 sebesar $29,7 \%$.

\section{SARAN}

1. Diharapkan agar industri rumah tangga "Berhias" dapat lebih memaksimalkan pemasaran agar dapat menambah volume penjualan sehingga nilai tambah yang diperoleh dapat lebih besar dari tahun ke tahun.

2. Kemungkinan dengan menambah kreasi dalam mengolah sampah anorganik dalam bentuk yang berbeda dapat menambah perhatian masyarakat dalam menggunakan produk yang dihasilkan industri rumah tangga "Berhias".

3. Disarankan produk yang di hasilkan Industri Rumah Tangga "Berhias" dapat bekerjasama dengan sekolah, perguruan tinggi dan pelatihan dalam rangka pengolahan sampah anorganik menjadi barang yang berguna.

\section{DAFTAR PUSTAKA}

Akmal. 2008. Mengukur Nilai Tambah. (aby98.files.wordpress.com/2008 107/strategicmanajemen-akmal2.doc). Diakses tanggal 29 Okto-ber 2013.

Anonim. 2010. Menyulap Sampah Kaca Menjadi Bisnis Daur Ulang. (http: //bisnisukm.com/sulap-sampah-kacamenjadi-bisnis-daur-ulang. html). Diakses tanggal 28 Oktober 2013g.

2011. Pengertian Daur Ulang. (Http://Lingkungan-121992. Blogspot.Com/2011/10/MenyulapSampah-Plastik-Menjadi.Html/) Diakses Tanggal 12 Agustus 2013.

2012. Pengertian Sampah Menurut Para Ahli. (Http://Www. Lepank.Com/2012/08/PengertianSampah-Menurut-BeberapaAhli.Html). Diakses tanggal 13 Agustus 2013.

2013. Potensi nilai ekonomis sampah. (http://blhd.tanjabbar kab. go.id/kategori/rehli/nilaisampah.html). Diakses tanggal 13 Agus-tus 2013.

Anwar. 2010. Perbedaan Sampah Organik dan Sampah Anorganik. (Http://Www.Buletinbelantara.Com/201 2/05/Sampah-Organik-Dan-

Anorganik.Html). Diakses tanggal 4 Oktober 2013.

Azis, Musdalifah. 2012. Pengertian Manajemen Operasional. (http://www. 
slideshare.net/musdalifah/manajemenoperasional1). Diakses tanggal 14 Februari 2014.

Budianas, N. 2013. Pengertian Economis Value Added (EVA), (Http://Nanangbudianas.Blogspot.Com 2013/02/Pengertian-Nilai-TambahEkonomis-Eva 6.Html). Diakses tanggal 27 Oktober 2013.

Daft. Richard L. 2012. Era Baru Manajemen. Jakarta: Salemba Empat.

Darwisroland. 2013. Pengertian Manajemen Operasional. (http://darwisroland.blogspot.com/2013/07/makalah -manajemen-produksi-danoperasi.html). Diakses tanggal 7 Februari 2014.

Galamsyah. 2012. Rumus yang digunakan dalam mengukur nilai tambah. (Http://Guruhalamsyah.Wordpress.Co m/2012/12/01/Kelompok-2-Nilai Tambah-Ekonomis/). Diakses tanggal 10 oktober 2013.

Gustina. I. 2010. Perbedaan Sampah dan Limbah. $\quad$ (Http://Health.Detik. Com/Read/2010/07/23/152038/14053 94/766/Apa-Beda-Sampah-DanLimbah). Diakses tanggal 4 Oktober 2013.

Handoko, T.Hani. 2003. Manajemen. Cetakan Kedelapan belas. Yogyakarta: BPFEYogyakarta.

Hasibuan, Malayu S.P. 2006. Manajemen Dasar. Jakarta: Bumi Aksara.

Pakpahan, E. Pengertian Value Added. (Http://Tugasakhiramik.Blogspot. Com/2013/05/PengertianEconomicValue-Added-Eva.Html). Diakses tanggal 27 Oktober 2013.

Prawirosentono, S. 2007. Pengantar Bisnis Modern. Jakarta: Bumi Aksara.

Riduwan. 2005. Dasar-dasar Statistika. Bandung: Alfabeta.
Suryana. 2003. Kewirausahaan. Jakarta: Salemba Empat.

Sustaining, Partnership, 2007. Pengolahan Sampah. (Http://Pkps. Bappenas.Go.Id/Attachments/Article/9 54/NOVEMBER\%20Reguler_SAMPA H_INDONESIA_L.Pdf). Diakses tanggal 27 Oktober 2013.

Thomas, W. 2008. Kewirausahaan Dan Manajemen Usaha Kecil. Jakarta: Salemba Empat.

Wiludjeng, Sri. 2007. Pengantar Manajemen. Yogyakarta: Graha IImu

Winardi. 2005. Entrepreneur Dan Entrepreneurship. Jakarta: Prenada Media. 